\title{
PRÁTICAS DE CONSULTORIA COMO METODOLOGIA DE ENSINO DA GESTÃO DE PEQUENAS EMPRESAS: A EXPRERIÊNCIA UNIFESSPA
}

Juliana Moreira Dos Santos ${ }^{1}$

Daiane Martins Teixeira ${ }^{1}$

Gustavo Passos Fortes ${ }^{1}$

Carlos Cesar Santos ${ }^{1}$

${ }^{1}$ Universidade Federal do Sul e Sudeste do Pará 


\section{PRÁTICAS DE CONSULTORIA COMO METODOLOGIA DE ENSINO DA GESTÃO DE PEQUENAS EMPRESAS: A EXPRERIÊNCIA UNIFESSPA}

Resumo: O presente relato técnico tem objetivo de apresentar os resultados do projeto Consultoria na Prática - Pré consultores. Tal projeto propõe a realização de pré-consultorias aos empreendedores da região de Rondon do Pará. As consultorias foram realizadas pelos discentes dos cursos da área de gestão de negócios da Universidade Federal do Sul e Sudeste do Pará e proporcionou a vivência no contexto empresarial alinhando teoria à prática. As atividades do projeto, contribui para a aproximação da UNIFESSPA com a comunidade local, com instituições de fomento ao empreendedorismo e com as micro e pequenas empresas locais. Incentivando o empreendedorismo universitário e a conscientização dos alunos da importância da consultoria organizacional como ferramenta complementar de aprendizagem. O referido projeto envolve 4 docentes; 71 discentes dentre eles 1 bolsista; 23 empresas que tiveram aproximadamente 171 ações sugeridas pelos os mesmos.

Palavras-chave: Consultoria. Empreendedorismo. Extensão universitária. 


\section{Introdução}

A expansão do ensino superior no Brasil provocou mudanças que exigem uma nova postura da academia, que possibilite a formação de profissionais habilitados e capazes de exercer seu papel na sociedade. Estas transformações, tal como afirmam Carvalho e Síveres (2013), asseveram a importância de uma formação preocupada com as questões sociais, ambientais e culturais, alinhadas à questão técnica da formação acadêmica.

A extensão universitária contribui para esse objetivo possibilitando ao aluno a participação em um processo educativo que articula o ensino e a pesquisa de forma indissociável e "viabiliza a relação transformadora entre Universidade e Sociedade" (DUCH; NOGUEIRA, 2006, p. 11). Assim, a extensão universitária funciona como uma catalizadora do ensino e pesquisa, compondo o tripé de sustentação das universidades (SÍVERES, 2013).

Costa, Baiotto e Garces (2013) estudaram as visões de estudantes da graduação de diferentes instituições de ensino no Brasil, com o objetivo de verificar a aprendizagem que eles constroem na realização de projetos de extensão. Os autores concluem que a participação em projetos de extensão permite aos estudantes universitários a consciência de seu papel como profissionais e como cidadãos, ou seja, a participação mais efetiva e sensível frente aos problemas sociais. Ao vivenciar o projeto de extensão, há uma troca simultânea de conhecimento entres professores e alunos, refletindo na comunidade por meio de uma constante transição de saberes (COSTA; BAIOTTO; GARCES, 2013).

Percebe-se que existe um grande afastamento entre teoria e prática nos cursos de Administração de Empresas, permitindo ao aluno cursar toda a graduação sem aplicação prática do conteúdo aprendido em sala de aula (ARAUJO et al., 2014; GUIMARÃES, 2015). Ao mesmo tempo em que os universitários estão afastados da realidade das empresas locais, as pequenas empresas da comunidade pouco se beneficiam do conhecimento produzidos dentro da universidade (CHIARINI; VIEIRA, 2012).

O curso de Administração de Empresas precisa estar alinhado com as necessidades e particularidades das empresas locais. Deve possibilitar que os discentes compreendam a comunidade pela ótica da gestão e do empreendedorismo. Ao mesmo tempo, o conhecimento produzido na universidade precisa de alguma forma beneficiar a comunidade (ARAUJO et al., 2014; GUIMARÃES, 2015). Nesse sentido, os alunos de administração, com orientação de seus professores, podem prestar serviços de consultoria organizacional aos empreendedores da região, com objetivo de alinhar a prática profissional na formação acadêmica, aprimorando o processo de ensino aprendizagem, ao mesmo tempo em que viabilizam a intervenção institucional na sociedade (SANTOS, 2010).

O projeto de extensão denominado "Consultoria na prática" proporcionou por intermédio dos discentes oportunidades de integração entre a universidade e a comunidade, estimulando o desenvolvimento e a divulgação dos conhecimentos teóricos advindos da academia. Portanto, o presente trabalho apresenta em formato de relato técnico os resultados do projeto de formação de consultores na Universidade Federal do Sul e Sudeste do Pará.

\section{Referencial Teórico}

A consultoria empresarial, segundo Crocco e Guttman (2005) é um meio de obter melhoria organizacional, revisão dos processos, diminuição dos custos e otimização dos recursos. A consultoria representa um contributo maior para o gerenciamento de empresas e
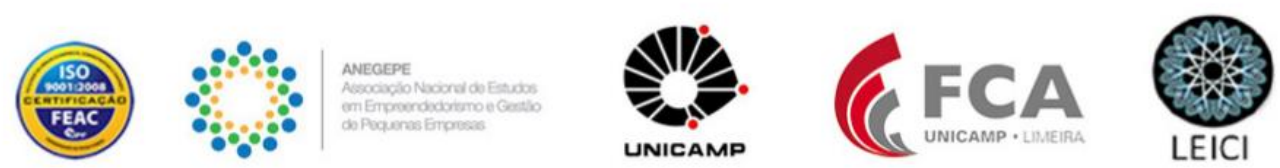
serve para fornecer uma estrutura mais profissionalizada para as micro empresas (SANTOS; GOES, 2015). A consultoria nesse sentido, muito além de proporcionar o aprendizado aos alunos da instituição, possibilita aos empreendedores o acesso a modelos e ferramentas de gestão.

Ainda nos anos 90, motivada pela ascensão do setor de serviços, a indústria da consultoria apresentou uma importante transformação, principalmente com a popularização e adaptação das ferramentas de gestão (CLARO et al., 2011). A mudança no modo de atuação dos consultores refletiu no relacionamento com as empresas contratantes, formatando as características que serviram de suporte para a configuração do setor nos dias atuais (OLIVEIRA, 2010; CLARO et. al., 2011).

A atividade de consultoria empresarial apresenta um crescimento espantoso como segmento do setor de serviços, possibilitando um ganho de competitividade para as pequenas empresas (PRIM; EHMKE, 2015). Os principais motivos pela devida ascensão de consultorias empresariais são: necessidade de maior conhecimento; desenvolver as competências e falta de tempo (CROCCO; GUTTMANN 2005; PRIM; EHMKE, 2015). Percebe-se então que a interação entre consultor e cliente é uma relação mútua de aprendizagem, desenvolvimento de competências, aplicação de conhecimentos e ferramentas. Assim, o cliente absorve novos conhecimentos fornecidos pelo consultor e o consultor tem a oportunidade de testar novos métodos de trabalhos (PRIM; EHMKE, 2015).

Muitos autores caracterizam a consultoria como um processo de aconselhamento, com finalidade de resolver problemas organizacionais na melhoria de processos e desenvolvimento da empresa (OLIVEIRA, 2010). De acordo com Crocco e Guttman (2005), a consultoria empresarial possibilita a melhoria organizacional por meio da revisão de processos, otimização dos recursos e inovação. A consultoria então pode ser vista como a construção de uma relação de ajuda, estabelecendo a definição do problema, o desenvolvimento de soluções, a proposta de intervenção, a orientação empresarial na aplicação de ferramentas de gestão e a proposta para uma recomendação final (OLIVEIRA, 2010).

A função do administrador é planejar, organizar, liderar e controlar as organizações no desenvolvimento estratégico de resultados práticos. Assim, a consultoria empresarial é uma importante função do profissional atualmente (BERVANGER; VISENTINI, 2017). Porém as universidades costumam formar administradores com poucas oportunidades de trabalhos práticos sem a preocupação de diminuir a distância entre o que se ensina em sala de aula e a prática no ambiente organizacional (ARAUJO et al., 2014; GUIMARÃES, 2015).

Existem diversas alternativas para que o estudante se insira numa atmosfera onde ele vivencie o ambiente de trabalho, ao mesmo tempo em que reflita sobre o que está aprendendo nas aulas. Uma delas é a vivência em consultorias orientada por professores experientes. Nesse mesmo sentido podemos citar exemplos de parcerias com o SEBRAE, com projetos de préconsultores, projetos de pesquisa-ação e o papel da Empresa Júnior. Todas essas iniciativas objetivam aliar a teoria à prática, desenvolvendo atividades de consultoria empresarial, complementando a formação acadêmica (MONTENEGRO, 2015; BERVANGER; VISENTINI, 2017; SEBRAE 2016).

A consultoria como atividade pedagógica, prevê a prestação de serviços principalmente, para micro e pequenas empresas (BERVANGER; VISENTINI, 2017). Apresenta-se aqui a possibilidade de ingresso do estudante de Administração na atividade de consultoria,

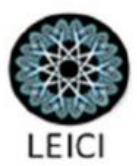


supervisionado pelos professores e profissionais no desenvolvimento dos exercícios, com o apoio da instituição de ensino e seus parceiros (BERVANGER; VISENTINI, 2017). Essas atividades possibilitam a formação completa do administrador ao tempo que diminui a lacuna entre o que se aprende na universidade e o que o mercado de trabalho exige do profissional (BERVANGER; VISENTINI, 2017).

Ao mesmo tempo em que facilita o aprendizado dos alunos, as atividades de consultoria empresarial possibilitam a aplicação do conhecimento construído na universidade. A comunidade local, por meio de atividades de extensão, é diretamente beneficiada por serviços gratuitos prestados por alunos e professores universitários (SILVA JÚNIOR et al., 2010).

\section{Desenvolvimento e Metodologia}

O presente trabalho relata a aplicação do projeto de extensão denominado "Consultoria na Prática - Pré-Consultores UNIFESSPA", desenvolvido e aplicado no Instituto de Ciências Sociais Aplicadas da Universidade Federal do Sul e Sudeste do Pará.

A adoção do formato de relato técnico no presente trabalho corrobora com Biancolino et al. (2012) por trata-se do produto final de um trabalho de intervenção em um contexto especifico que descreve uma experiência em organizações. Segundo os autores, apesar das diferenças quanto ao artigo cientifico tradicional, o relato técnico deve ser escrito com rigor cientifico e metodológico e tem o objetivo de apresentar de forma simples os fatos ocorridos nas empresas ou projeto. Constitui-se então um modelo de construção de conhecimento baseado em práticas desenvolvidas nas organizações (BIANCOLINO et al., 2012).

O projeto em questão foi desenvolvido junto aos alunos do Instituto de Ciências Sociais Aplicadas (ICSA) da Universidade Federal do Sul e Sudeste do Pará (UNIFESSPA). Propõe que os alunos apliquem ferramentas de gestão em micro e pequenas empresas, atuando como consultores voluntários em áreas aprendidas no decorrer do curso. Inicialmente foram ministradas aulas expositivas, workshops e oficinas de nivelamento com os alunos sobre conteúdos como: Aspectos de Consultoria Empresarial, abordagem de clientes, apresentação do projeto, aplicação de diagnósticos, técnicas de entrevistas e confecção de relatórios de devolutiva.

Ao mesmo tempo em que o projeto contribui para o desenvolvimento acadêmico e prático dos alunos, possibilita o apoio aos empreendedores locais e a consequente disponibilização do conhecimento produzido na universidade. O projeto propõe a atuação dos alunos como consultores e orientadores empresariais com o auxílio e supervisão direta de professores com experiência em consultoria e gestão estratégica.

Os alunos participantes assinaram um termo de voluntariado por meio do qual se comprometeram que a prestação de serviço destinar-se-ia exclusivamente para fins de aprendizado e sem contrapartida financeira. Como forma de aprendizado prático, os alunos aplicaram consultorias gratuitas nas micro e pequenas empresas no município dede Rondon do Pará, no estado do Pará. A área dessas consultorias vinculadas aos conteúdos e ferramentas aprendidas a uma das disciplinas que o aluno estivesse cursando ou já houvesse cursado.

Em todas as etapas da consultoria os alunos foram supervisionados e orientados pelo professor da disciplina Consultoria Organizacionais e por mais três professores colaboradores do projeto e responsáveis pelas disciplinas de Estratégia Empresarial, Gestão da Inovação,

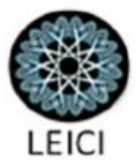


Gestão de Projetos e Contabilidade Gerencial. A dinâmica do projeto consiste em 5 fases descritas no Quadro 1- Etapas e dinâmica do projeto.

\section{Quadro 1 - Etapas e dinâmica do projeto}

\begin{tabular}{|c|c|c|}
\hline \multicolumn{2}{|c|}{ Etapa } & Dinâmica \\
\hline 1 & $\begin{array}{c}\text { Capacitação e aprendizado teórico } \\
\text { sobre consultoria organizacional }\end{array}$ & Aulas expositivas, workshops, debate em sala de aula. \\
\hline 2 & $\begin{array}{c}\text { Prospecção de empresas e adesão } \\
\text { ao projeto }\end{array}$ & $\begin{array}{c}\text { Mapeamento de possíveis clientes; Visita prospectiva } \\
\text { às empresas da comunidade; Apresentação do projeto } \\
\text { aos empreendedores; Assinatura do termo de adesão. }\end{array}$ \\
\hline 3 & $\begin{array}{c}\text { Diagnóstico empresarial e relatório } \\
\text { de devolutiva }\end{array}$ & $\begin{array}{c}\text { Workshops sobre técnicas de entrevistas; observação; } \\
\text { construção de ferramenta de diagnóstico empresarial; } \\
\text { Consolidação dos dados; Confecção do relatório de } \\
\text { devolutiva. }\end{array}$ \\
\hline 4 & $\begin{array}{c}\text { Feedback e Construção do plano } \\
\text { de ação de melhoria }\end{array}$ & $\begin{array}{c}\text { Preparação da visita de feedback; Construção das } \\
\text { sugestões em forma de plano de ação; Reunião de } \\
\text { devolutiva; validação das ações propostas. }\end{array}$ \\
\hline 5 & $\begin{array}{c}\text { Acompanhamento das ações } \\
\text { propostas }\end{array}$ & $\begin{array}{c}\text { Visitas periódicas de acompanhamento do plano de } \\
\text { ação das empresas atendidas. }\end{array}$ \\
\hline
\end{tabular}

Fonte: Elaborado pelos autores (2018)

Após a intervenção os alunos apresentaram em forma de estudo de caso, caso de ensino ou relato técnico os resultados e as experiências aprendidas com o projeto contemplando os seguintes itens: 1 - Apresentação da empresa; 2 - Breve histórico do empreendedor e do empreendimento; 3 - Diagnóstico empresarial (por área); 4 - Ferramentas que foram sugeridas e utilizadas pela empresa; 5 - Histórico da intervenção; 6 - Resultados e conclusões. 7 Dificuldades e impressões sobre a atividade.

\section{Contexto do Projeto}

Em cinco de junho de 2013, por meio da Lei no 12.824 criou-se a Universidade Federal do Sul e Sudeste do Pará (UNIFESSPA), que foi o desmembramento da Universidade Federal do Pará (UFPA), Campus Universitário de Marabá. A UNIFESSPA é a universidade federal mais nova do Brasil e cumpre um importante papel no desenvolvimento econômico e social da região norte.

Nesse sentido, sua criação foi pautada por princípios orientadores que visam à integração da região e o desenvolvimento dos municípios que perfazem a microrregião de Marabá (mesorregião do sudeste paraense) e seu entorno. Dentre esses princípios, destacam-se o desenvolvimento regional integrado; o acesso ao ensino superior como fator decisivo para o desenvolvimento das capacidades econômicas e sociais da região; a qualificação profissional; o desenvolvimento do ensino, da pesquisa e da extensão como condição de existência de um ensino crítico, investigativo e inovador.

Em 2014, o Instituto de Ciências Sociais Aplicadas (ICSA) iniciou as primeiras turmas dos cursos de ciências contábeis e administração, sediado no campus de Rondon do Pará. Hoje, o Instituto conta com cerca de 320 discentes, seis técnicos administrativos e 23 docentes. $\mathrm{O}$ 
desafio agora é levar o conhecimento produzido em sala de aula para a comunidade de Rondon do Pará, mais especificamente aos empreendedores locais.

Rondon do Pará possui 35 anos de emancipação e está situado na mesorregião do sudeste paraense. Segundo dados do IBGE (2017), a cidade possui cerca de 50.925 habitantes. Em meados dos anos 2000, a economia do município girava em torno de madeireiras e carvoarias que diminui consideravelmente devido as pressões sociais e ambientais vigentes. Atualmente o contexto econômico do município é alicerçado pelo setor agropecuário, e um comercio varejista expressivo, pelo qual constitui 2001 micro e pequenas empresas formais.

\section{Avaliação e impactos parciais do Projeto}

\section{Quadro 2 - Números do Projeto}

\begin{tabular}{|l|c|}
\hline \multicolumn{2}{|c|}{ Números do Projeto de } \\
\hline Empresas atendidas & 23 \\
\hline Total de Alunos & 71 \\
\hline Alunos bolsistas & 01 \\
\hline Alunos voluntários & 20 \\
\hline Professores envolvidos & 04 \\
\hline Visitas realizadas & 168 \\
\hline Ações Sugeridas & 171 \\
\hline Ações executadas & 15 \\
\hline \multicolumn{2}{|c|}{ Fonte: Elaborado pelos autores (2018) }
\end{tabular}

O projeto contemplou vinte e três empresas com o total de setenta e uns alunos participantes, divididos entre bolsistas, voluntários envolvidos. Foram realizadas em média cento e sessenta e oito visitas, para o acompanhamento das ações sugeridas. Nesse sentido, os pré-consultores desenvolveram suas atividades com intuito de atender as necessidades identificadas nas empresas.

Visando atender o tripé da Universidade que encontra-se alicerçado no ensino, pesquisa e extensão, o projeto envolveu além das consultorias, a criação da Empresa Junior que já em atuação no mercado. Paralelamente as ações supracitadas possuem finalidade de integrar os discentes de administração com a realidade empresarial local.

\subsection{Perfil das empresas e visão dos alunos}

Após uma breve análise, foi possível constatar que as referidas empresas, se caracterizam como negócios de pequeno porte e devido esse perfil possui características similares. A vista disso, faz-se oportuno explanar que a maioria das empresas estudadas, apresentaram deficiência na gestão, recursos financeiros e humanos limitados, estrutura organizacional simples, ausência de planejamento, capacidade baixa de inovação e aversão a mudança. Em contrapartidas, essas empresas, são flexíveis e possuem capacidade responder as demandas do mercado rapidamente, devido sua proximidade como os clientes. Observa-se uma diversidade no setor de atuação das empresas atendidas pelos discentes. Desta forma, foi possível notar que 02 empresas estão inseridas no ramo alimentício, 01 no segmento de 
calçados, 04 no setor farmacêutico, 04 no ramo de móveis e eletro domésticos, 03 em confecções, 03 no segmento de variedades, 01 em academia, 01 em consultoria, $01 \mathrm{em}$ horticultura, 01 no setor de informática, 01 em cosméticos e 01 no segmento de materiais de construção.

Face o exposto, compreende-se, que do total de empresas atendidas, 17,3\% são respectivamente dos setores farmacêuticos e de moveis e eletro domésticos. Esse dado permite um olhar diferenciado no desenvolvimento das ações propostas, a fim de manter as empresas competitivas no mercado.

Para complementar o relato, faz-se oportuno relatar depoimentos das experiências de alguns alunos em relação a importância da vivência prática no meio acadêmico, proporcionada pelo projeto Consultoria na Prática. Os nomes dos pré- consultores foram omitidos para garantir privacidade aos mesmos:

"Interessante foi perceber como o processo de consultoria é importante, mesmo quando a solução parece óbvia. Pois vimos que as vezes a solução óbvia não foi aplicada pois o empreender não viu o problema e outras por não achar que a solução seria eficaz até ouvi-la da boca de outra pessoa" (Pré-Consultor A).

"A experiência com a atividade de consultoria nos trouxe não apenas conhecimentos, foi além disso, criamos um relacionamento profundo que foi essencial para o desenvolvimento para nossas atividades" (Pré-Consultor B).

"O projeto de consultoria permitiu uma visão ampla do funcionamento das empresas, de modo a ajuda-las enquadrarem em um contexto que possam obterem êxito. Foi uma experiência bastante enriquecedora" (Pré-Consultor C).

\subsection{Ações sugeridas e executadas}

\section{Quadro 3 - Necessidades Identificadas}

\begin{tabular}{|l|c|c|}
\hline \multicolumn{1}{|c|}{ Necessidades identificadas } & Frequência & \% \\
\hline Utilizar recursos de Marketing & 31 & 18,1 \\
\hline Melhorias no layout da empresa & 16 & 9,3 \\
\hline Estabelecer planejamento estratégico & 12 & 7,0 \\
\hline Controlar o fluxo de caixa & 11 & 6,4 \\
\hline Criar cultura organizacional & 9 & 5,3 \\
\hline Capacitação dos colaboradores & 8 & 4,7 \\
\hline Instalação de um sistema de gerenciamento & 8 & 4,7 \\
\hline Cadastro dos clientes & 7 & 4,0 \\
\hline Outras & 69 & 40,3 \\
\hline
\end{tabular}

Fonte: Elaborado pelos autores (2018)

Embora as necessidades identificadas pelos discentes tenham sido diversas, optou por destacar as com maior frequência. Dessa forma, a tabela acima apresenta quais foram essas e a quantidade de vezes em que as mesmas foram identificadas nas respectivas vinte e três empresas, ressaltando que a ordem foi colocada do maior para o menor como forma de tornar mais evidente. Com isso, na sequência ficou $1^{\circ}$ a utilização de recursos do marketing, com 18,1\%; $2^{\circ}$ Melhorias no layout da empresa, 9,3\%; $3^{\circ}$ Estabelecer planejamento estratégico, $7,0 \% ; 4^{\circ}$ Controlar o fluxo de caixa, $6,4 \% ; 5^{\circ}$ Criar cultura organizacional, $5,3 \% ; 6^{\circ}$ Capacitação 
dos colaboradores, 4,7\%; $7^{\circ}$ Instalação de um sistema de gerenciamento, 4,7\%; $8^{\circ}$ Cadastro dos clientes, $4,0 \%$.

\subsection{Casos de Destaque}

Os primeiros resultados já podem ser observados por meio das ações que foram sugeridas pelos pré-consultores e executadas pelas micro e pequenas empresas. Apresenta-se a seguir 3 casos de destaque para o projeto.

\subsubsection{Empresa Café com Prosa}

O Café com Prosa é micro empresa que atua no setor alimentício e iniciou suas atividades no mês de abril do ano de 2017 de maneira informal. A referida empresa, tem como público alvo, clientes da classe A e B e seu objetivo é fornecer cafés especiais e acompanhamentos de qualidade para os consumidores. Após quinze dias de funcionamento improvisado, a empreendedora observou a oportunidade de implementar um negócio mais sofisticado atendendo as demandas dos clientes e inovando com um cardápio diferenciado para o contexto que está inserido. Face ao exposto, a empresa foi contemplada a participar do projeto.

Sendo assim, o diagnóstico empresarial, juntamente com uma conversa inicial e observações feitas na empresa, permitiram uma visão sistêmica do negócio que foram essenciais para uma abordagem detalhada de ações que promoveriam mudanças na organização. Com isso, os pré consultores realizaram a devolutiva propondo oito ações, das quais já foram executadas cinco, até a o dia 05/02/2018. Cabe aqui destacar as sugestões aceita e operacionalizadas pela gestora; (1) padronização dos uniformes dos colaboradores, (2) estabelecimento da cultura organizacional, (3) aprimoramento do layout interno, (4) treinamento de colaboradores e (5) slogam da marca.

\subsubsection{Empresa Bistrô da Sula}

O restaurante Bistrô da Sula enquadra-se na categoria de empreendedor individual, iniciou seus trabalhos no dia 05 de janeiro de 2016, formalmente com o objetivo de fornecer um cardápio com pratos mais requintados, haja vista que o município de Rondon do Pará no período mencionado ainda não dispunha de restaurantes que apresentassem a mesma proposta. Devido a um perfil de empresa mais sofisticada, os seus clientes potenciais são especificamente pessoas das classes A e B. Partindo dessa premissa, a referida empresa foi comtemplada para participar do projeto de consultoria, pelo qual mediante aos diagnósticos realizados, foram sugeridas seis ações, elencadas por ordem de prioridade, com intuito de contribuir para possíveis melhorias na organização. Dentre essas ações, quatro foram operacionalizadas, sendo elas: 1) Descentralização de funções; 2) Instalação do sistema de Gerenciamento; 3) Restruturação do layout; e 4) Aplicação da ferramenta de melhoria contínua - o PDCA.

\subsubsection{Farmácia Santa Maria}

A Farmácia Santa Maria, enquadra-se como micro empresa - ME, fundada em 06 de julho de 2015, por meio de um desejo da empreendedora em possuir um negócio próprio. A empresa tem seus produtos e serviços direcionados a pessoas de classes B e C, pois são vistos como os clientes potenciais da organização. Dado isso, por meio do Projeto de Pré-Consultoria, foi elaborado um diagnóstico e posteriormente desenvolvido ações de acordo com as

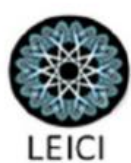


necessidades mais urgentes da empresa, considerando também as condições de execução. Cabe ressaltar que em razão das necessidades apontadas, foram propostas mais ações quando comparadas com as outras empresas listadas, sendo especificamente dez ações e dentre essas apenas quatro foram operacionalizadas, conforme descritas a seguir: (1) Utilização de sistema de gerenciamento empresarial; (2) Aplicação do controle financeiro; (3) Atualização dos dados dos clientes e (4) Buscar formas de atender à necessidade dos clientes. Pode-se concluir que embora a quantidade de ações tenha sido significativamente maior, a Farmácia Santa Maria demonstrou resistência em executá-las.

\section{Considerações finais}

Este relato teve como objetivo apresentar resultados do projeto consultoria na prática que buscou contribuir com a comunidade local por meio do acompanhamento de ações voltadas ao fomento do empreendedorismo e da gestão empresarial no município de Rondon do Pará, privilegiando a consolidação do conhecimento nos discentes envolvidos, o fortalecimento dos empreendimentos da comunidade e o cumprimento da tríplice responsabilidade da universidade com a pesquisa, o ensino e a extensão.

Dentre as ações realizadas durante o projeto, observa-se a relevância da inserção do campus universitário no interior do estado Pará, mediante a carência dos empreendedores da região no domínio de ferramentas básicas e intermediárias de gestão. A dinâmica bem sucedida de ensino aprendizagem vivenciada pelos alunos que se destacam na região como profissionais da área de gestão e como empreendedores ao capitanearem a fundação do Movimento Empresa Junior no Campus.

Neste sentido, considera-se este relato técnico uma contribuição relevante do ponto de vista didático-científico para a construção de futuros modelos de projetos que busquem contribuir para a consolidação de programas multidisciplinares com foco em ações de intervenção na comunidade. Para região por oferecer um panorama das principais fragilidades dos empreendimentos locais, fomentando a criação de programas voltado ao fortalecimento das MPE's que busque a criação de novos postos de trabalho, a melhoria da qualidade de vida e a solidificação da economia da região.

\section{Referências}

ARAUJO, G. D.; da SILVA, A. B.; de LIMA, T. B.; BISPO, A. C. K. A. Currículo e vínculos teoria-prática: reflexões no processo ensino-aprendizagem em um curso de graduação em administração. Revista de Gestão do Unilasalle, v. 3, n. 2, p. 09-31, set. 2014.

BERVANGER, E.; VISENTINI, M. S. Publicações científicas brasileiras sobre empresas juniores na área de administração: um estudo bibliométrico. REGE-Revista de Gestão, v. 23, n. 3, p. 197-210, 2016.

CARVALHO, F. G. B.; SÍVERES, L. A Dinâmica Motivacional no processo de aprendizagem na extensão universitária. In: SÍVERES, L (Org.). A Extensão universitária como um princípio de aprendizagem. Brasília: Liber Livro, 2013. 
CHIARINI, T.; VIEIRA, K. P. Universidades como produtoras de conhecimento para o desenvolvimento econômico: sistema superior de ensino e as políticas de CT\&I. Rev. Bras. Econ. Rio de Janeiro, v. 66, n. 1, p. 117-132, Mar. 2012.

COSTA, A. A. C.; BAIOTTO, C. R.; GARCES, S. B. B. Aprendizagem: o olhar da extensão In: SÍVERES, L (Org.). A Extensão universitária como um princípio de aprendizagem. Brasília: Liber Livro, 2013.

CLARO, J. A. C.; JESUS, M. A. S.; LOPES, C. P.; BARRETO. R. M. Consultoria organizacional: utilização do marketing de relacionamento pelas pequenas empresas de consultoria e pelos consultores autônomos na busca de competitividade. Revista da Micro e Pequena Empresa, v. 5, n. 3, p. 21-39, 2011.

CROCCO, L.; GUTTMANN, E. Consultoria Empresarial. São Paulo. Saraiva. 2005.

GUIMARÃES, J. de C. A relação teoria-prática no currículo dos cursos de administração da UFPI à luz da lógica do mercado, 2015. Tese (Doutorado em Educação) - Faculdade de Educação, Universidade Federal do Rio de Janeiro, Rio de Janeiro, 2015.

IBGE. Perfil das cidades. Brasil, 2017. Acesso em: 02/03/2018 ás 20:31. Disponível em: https://cidades.ibge.gov.br/brasil/pa/rondon-do-para/panorama

MONTENEGRO, C. B. Da Teoria à Prática: Projeto Pré-Consultores, Um Estudo Sobre a Perspectiva de Prática Profissional na Formação Acadêmica. 25 ${ }^{\mathbf{a}}$ Conferência da ANPROTEC de Empreendedorismo e Ambientes de Inovação. Mato Grosso, n. 1, 2015.

DUCH; NOGUEIRA, M. D. P. Extensão universitária: diretrizes conceituais e políticas. Belo Horizonte: Editora da UFMG, 2006.

SÍVERES, L (Org.). A Extensão universitária como um princípio de aprendizagem. Brasília: Liber Livro, 2013.

OLIVEIRA, D. de P. R. Manual de consultoria empresarial: conceitos, metodologia e práticas. São Paulo: Atlas, 2001.

PREFEITURA MUNICIPAL. Secretária de Finanças. Rondon do Pará, 2017.

PRIM, A. L.; EHMKE, R. M. A influência da cultura organizacional no processo de consultoria empresarial. Revista Organizações em Contexto, v. 11, n. 21, p. 345-366. 2015.

SANTOS, S. C. O processo de ensino-aprendizagem e a relação professoraluno: aplicação dos" sete princípios para a boa prática na educação de Ensino Superior". REGE Revista de Gestão, v. 8, n. $1,2010$.

SANTOS, C. T. De A.; GÓES, A. O. S. Consultoria e empreendedorismo: uma abordagem estratégica. Revista Cadernos de Aulas do LEA, n. 4, p. 1-15, Ilhéus - BA, nov. 2015. 